MATEC Web of Conferences 3, 01006 (2013)

DOI: $10.1051 /$ matecconf/20130301006

(C) Owned by the authors, published by EDP Sciences, 2013

\title{
Thermodynamic and structural studies of the solid deposit formation in paraffinic petroleum cuts
}

\author{
M. Dirand, D. Petitjean and M. Bouroukba \\ LRGP (UMR CNRS 7274), ENSIC, Université de Lorraine, 1 rue Grandville F54001 NANCY Cedex
}

\begin{abstract}
A general review [1, 2] is presented concerning jointly the crystallographic structures and the transition physicochemical data ( $\mathrm{T}_{\text {fus }}, \Delta_{\text {fus }} \mathrm{H}, \Delta_{\text {fus }} \mathrm{S}, \Delta_{\mathrm{eb}} \mathrm{H}, \Delta_{\text {sub }} \mathrm{H}, \mathrm{Cp}$ ) in the pure normal alkanes, as well as the structural and thermodynamic behavior of their synthetic binary, ternary and multinary model mixtures and of real petroleum waxes, particularly the solubility and mixture properties [3-6]. A major part of the structural and thermodynamic data of the literature and our experimental results are listed from methane up to the alkane with carbon atom number equal to $390[1,2]$ as well as their variations versus the atom carbon number.

The experimental results [3] and those of literature concerning the pure n-alkane dissolution enthalpies allow to determine the enthalpy of the formation of one or several crystallized solid solutions of the mixtures [4] and to highlight the influence of the characteristic parameters of the paraffinic distribution (theoretical average chain length, n-alkanes number, monophasic or polyphasic state) on the excess properties in the solid state. This data bank permits to test the predictive capacities of the UNIQUAC thermodynamic model. After modifying the expression of the interaction energy to take into account the effect of the size difference between the n-alkanes of the mixtures and the internal disorder induced by the nalkane length distribution, this model give very good results for the prediction of the excess enthalpy of complex multialkane samples [4].
\end{abstract}

\section{References}

1. M. Dirand, M. Bouroukba, V. Chevallier, D. Petitjean, E. Behar, V. Ruffier-Meray, Review of J. Chem. Eng. Data 47115 (2002)

2. M. Dirand, M. Bouroukba, A-J. Briard, V. Chevallier, D. Petitjean, J-P. Corriou, J. Chemical Thermodynamics 341255 (2002)

3. A-J. Briard, M. Bouroukba, D. Petitjean, M. Dirand, J.Chem. and Eng. Data 481574 (2003)

4. A-J. Briard, M. Bouroukba, M. Dirand, J. Chem. and Eng. Data 49899 (2004)

5. A-J. Briard, M. Bouroukba, D. Petitjean, M. Dirand, J. Chem. Eng. Data 491201 (2004)

6. A-J. Briard, M. Bouroukba, D. Petitjean, N. Hubert, J.C. Moïse, M. Dirand, Fuel 85764 (2006) 